\title{
Ana Crăciunescu
}

\section{Discursive Appronches of "Space," "Place," and "Land" in Touristic Audio-Visual Advertising}

\begin{abstract}
Tourism at large represents a massive exchange of signs that are meant to represent and stand for a signified place as a totemic recognition of identity. In our paper we envisage to debate on the relocation of the anthropological notions such as 'space', 'place' and 'land' that shape identities in a semiotic approach on the media map of tourism advertising. We shall demonstrate that local identity is still submerged to postcolonial intrusions, while the techniques of promotional language are deployed in a ubiquitous understanding of the tourist's gaze.

Keywords: Promotional Language of Tourism; Place; Land; Discourse Analysis; Postcolonialism; Audio-Visual Advertising; Identity.
\end{abstract}

\section{ANA CRĂCIUNESCU}

"Ștefan cel Mare" University of Suceava, Romania anna_coo@yahoo.com

DOI: $10.24193 /$ cechinox.2020.38.20

\section{Discourse and Tourism: Cross- Disciplinary Epistemologies}

$\mathrm{D}^{\mathrm{i}}$ iscourse, a controversial, yet organized in its own laws of ethics of functioning as well as within its role of societal meaning generator and directory of norm, represents, since its recognition as a discipline per se, around the 60's, a wide, complex, contextualized form of expressing identities. Discourse emerges from several other basic fields (rhetoric, philosophy, linguistics etc.) and also constitutes a frame of research when applied to various disciplines, such as tourism and, more specifically, audio-visual tourism advertising, as in our case. In this light, the researcher's ethos determines us to describe the reason of our research method for the issue debated in the present paper.

In 1996, G. Dann publishes The Language of Tourism. A Sociolinguistic Perspective, a referential study that has certainly changed or rather organized the notions of promotional strategies in tourism for many scholars engaged around the field (economists, advertisers, linguists, sociologists etc.). Dann draws four perspectives ${ }^{1}$ 
of tourism and their sociolinguistic equivalent; the author seizes, thus, the complexity of tourism and its interdependence with contact disciplines as well as its impact over them. At the same time, several years earlier, in 1989, MacCannel noticed a strong bound between semiotics and tourism as "both have implications concerning the Other in global sociocultural arrangements" (Apud Dann, 1996: 5).

In this light, we already trace two fundamental approaches of tourism that complete and include each other. On one hand, Dann demonstrates that tourism has developed an autonomous promotional language, tributary to social experiment that provides the ethno-cultural basis for contextualized insertion of the linguistic/ symbolic pattern and classified by the author (Dann, 1996) in the category of Techniques of the Language of Tourism (verbal, visual, verbal and visual combined). On the other hand, when examined at its global scale, that is where the text meets the image in order to recreate the semantic and semiotic meaning, discourse of tourism advertising emerges. As a difference from the promotional language of tourism that imbues neutrality to a certain extent as prototyped by standard marketing and linguistic studies, the discourse of tourism advertising has the ability to challenge the most subtle tones of today's socio-political or ethnic-gender issues. Just as Thurlow notices, it is our responsibility to observe and take act of these sociolinguistic permutations and their impact in creating identities:

As scholars of language-in-society, we are therefore necessarily obliged to review the bread-and-butter material of our work. Specifically, we are needing to rethink - and, in some cases, to ditch altogether - some of the central tropes of our field such as 'community', authenticity', 'identity' and, indeed, 'language' and 'society' themselves. In this regard, Jan Blommaert (2005) and Ben Rampton (2009), amongst others, have both written about the need for a sociolinguistics or discourse analysis that is better able to account for the hybrid, the translocal, the spectacular, the idiosyncratic, the creative, and the multimodal (cf. Kress and van Leeuwen, 2001, on this last point). (Thurlow and Jaworski in Coupland, 2010:255)

This form of global semiotic capital - the tourism advertising discourse - attracted the preoccupation of scholars from various disciplines over the last years. The linguistic dimension at the intersection of the economic and social ones prompts Bourdieu's theory of sign exchange as valid, in our opinion. It even alerted anthropologists who expressed their direct observation of the touristic phenomenon in assertions such as: the 'tourist's gaze'(Urry, 2002, 2011) or 'tourist's syndrome' (Bauman, 2003). Preoccupations have extended from terms such as identity and community to otherness and orientalism, as tourism distinguishes also for playing a decisive role in shaping national or local identities, either in its creation as well as in its disappearance. At the same time, postcolonial studies completed the picture with important contributions. The very conflict perspective included by Dann in his classification transposes tourism at large into a clear form of neo/postcolonial discourse in the case of the countries - former colonies. For instance, in a sociological study, two of the selected most important approaches of tourism, are: "tourism as a type of ethnic relations" and "tourism as a form of neocolonialism” (Cohen, 1984: 376). 
Nevertheless, Pritchard and Jaworski realized the importance of studying discourse as a part of social and linguistic manifestation of tourism because:

[...] discourse and communication are also products of social relations and we need to explore and understand how their meanings have been constructed and used across the totality of human experience - and that includes tourism experiences (Jaworski, A.; Pritchard, A., 2005: 2).

The fact that discourse analysis seems to have been embracing tourism as an important generator of study material pretty recently (Cf. Ibidem) represents an important indicator in our research methodology options' evaluation. The 'discursive turn' (Idem: 5) in tourism studies opens a broadened interdisciplinary approach with a wider understanding that would decode more accurately meanings (semioticians), needs (marketers) and identities (anthropologists) for both specialists and tourists/hosts. Thus, we are preoccupied to motivate the choice of a research method that is common to both tourism and discourse in the context of tourism audio-visual advertising eventually. We could assert that the latter incorporates to a large extent the 'symbolic capital' of Bourdieu, due to its pragmatic side; so tourism stands as a double source of economic and signs exchange, either through its practicing or its promotion. In this sense, we have developed a scheme starting from the semiotic constitutional model after A. Greimas that we have entitled The semio-promotional circuit of tourism (Crăciunescu, 2018: 74-5).

In the postindustrial capitalist era, not only is tourism mainly semiotic, focusing on signs exchange, but it also sells mediatized image representations of the destinations that are tautologically reiterated in the tourists real experiences:

[...] the tourist imagination and tourist practices are always heavily (in) formed by - and prefigured in - the heavily mediatized representations of television holiday programmes, travel brochures, newspaper travelogues, postcards, guidebooks and so on (see Thurlow and Jaworski 2010). In this way, as Mike Crang (1999: 361) explains, "a structure of expectation is created, where the pictures circulating around sights are more important than the sites themselves [...]. (Thurlow, Jaworski, in Coupland, 2010: 297-8)

The consumption of these advertising signs might lead to what Urry named, in the case of photography, the "hermeneutic cycle', manifested in the destination, while "the tourist linguascape' (Jaworski et al. 2003) thus serves as an extension of the tourist gaze (Urry 2002, after Foucault 1976), the socially organized, systematized and disciplining ways in which tourism is structured and learned" (Idem: 298).

In this view, we may argue that it is within the space of the advertising that the dislocation and commodification of tourism language (Cf. Idem) take place. As each space is attributed a symbolic and meaning dimensions, the space of the advertising can constitute a space where the relations tourists-hosts manifest under a linguistic norm that may be different from the one in the destination. But the question of space will be further analyzed in the next chapter. 
The main aim here is to plead for a qualitative research method in favor of the quantitative one, as the latter does not provide interpretation over the subtle dimensions of the zoon semiotikon (Bruno) in a global context and his/her identities within the various communities:

Naive quantification paid little attention to gender, ethnicity, age, class or able-bodiedness while being overly concerned with theorizing across the entire social world. The differences which exist within and between all communities were given little attention despite, it is argued, their being critical to the understanding of social life. (Phillimore, Goodson, 2004: 32)

The role of the 'bricoleur', term attributed to the researcher by Denzin and Lincoln (Apud Idem: 34) is to answer the three 'ontological' questions ${ }^{2}$ and choose a suitable paradigm that brings discourse and tourism on a common track of research; on the other hand, despite the suspicions, scholars in tourism were encouraged to embrace more vividly a qualitative research. The association between tourism and discourse as a contact discipline involving others such as anthropology or semiotics would be a solution for increasing the variety and eligibility of qualitative research in tourism:

Research and discourse relating to tourism remain multidisciplinary, with a range of foci, approaches and styles that are not always congruent with one another. [...] this may give the field dynamism and potentially offer new opportunities for cross-fertilization of ideas, practices and processes. (Idem: 37 )

As our focus is much alleged to the ontological question, the chosen research paradigm should take into consideration the categorization of the virtual space of the destination's image and its role, depicted schematically by our Promotional Circuit of tourism of the tourism advertising (Crăciunescu, 2018). This very virtual space, in correlation with the interrelated terms of place and in a nexus to the identity in community, an issue of tourism as a postcolonial discipline as well, might lead our research paradigm toward yet unexplored qualitative methods in tourism. As in the scholars' opinion:

While a number of researchers have come to conclusions about the rising role tourism plays in our local representation of self and society (Selwyn 1996), tourism researchers have been neither theoretically nor methodologically advanced in the ways in which they have probed the various ontological identifications which exist between 'population' and 'place', and the various interconnectivities which lie between 'culture' and 'power' (Cohen 1984; Crick 1989; Featherstone 1995). (Hollinshead in Goodson, Phillmore, 2004: 65)

This would, moreover, advocate for the first sociolinguistic perspective of Dann: the perspective of authenticity - tourism as a language of identification. In a substantial article on the ontological question in tourism, Hollinshead structures in a table the 'Common ontological issues in tourism issues' divided 
into two main categories: sample issue in tourism setting/scenario and its equivalent sample - associated areas of uncertainty in scenarios seeing/experiencing/meaning/knowing/being (Hollinshead in Goodson, Phillmore, 2004: 86). Three of these samples are of interest in our paper as well, transferred in the setting of the virtual manifestation within the tourism advertising:

- The deep and often hidden meaning, in foreign places, of sites and stories of the resident host population there. (Ibidem)

- The large, long-standing and highly disempowering ways in which the tourist-producing West has continued to Other specific populations. (Ibidem)

- The frequently enigmatic and inconstant symbolic objects/places/events of signs/markers/objects in different societies, as serviced in international tourism. (Ibidem)

We consider that this rather "interpretive-phenomenological inquiry" (Ibidem) goes hand in hand with the deductive-empirical method of discourse analysis. We shall apply our 'samples in tourism setting/ scenario' on a constituted corpus representative for the recent development discourse of tourism advertising constructed on the larger background of the discourse of power (media and colonial).

\section{Space and Place: Ontological Interactions}

$\mathrm{T}$ his global-scale phenomenon, tourism, has long preoccupied scholars from different fields and we may advance it as a space in itself. A space of production and interaction that includes, territorially speaking, the nation-states of emergent tourist and the nation-states of the destinations. Secondly, we can also include the space of the individual-tourist, that is his/ her environment and the space of the individual-host. Thirdly, we are interested in the culturally inscribed space of the communities, as culture represents "a pervasive dimension of discourse that exploits difference to generate diverse conceptions of group identity" (Appadurai, 1996: 13). Our aim is to understand the abstract notion of identity as a performed space of the Self and manifested within places. The impersonality of space results hereby and interests us only as a performing frame for the place. As Lefebvre tries to define the productivity of space in linguistic terms, we are even more persuaded that the discourse appears at the level of revealed places as embodied interactions between individuals, memories and representations. De Certeau compares travel as "the return to nearby exoticism by way of a detour through distant places, and the discovery of relics and legends" (Certeau, 1984: 107) to the linguistic processes within the text that seems to travel towards a syncopated margin. Thus, in a Freudian acceptation, he notes that "to practice space is thus to repeat the joyful and silent experience of childhood; it is, in a place, to be other and to move toward the other" (Idem: 110).

A place remains to a certain extend a story, in the same author's view; yet "every story is a travel story - a spatial practice" (Idem: 115); in a rather saussurian understanding, De Certeau considers that "in relation to place, space is like the word when it is spoken" and "in short space is a practiced place" (Idem: 117). 
Nevertheless, our thesis reciprocates the theory of $\mathrm{H}$. Bhabha on culture with theories of discourse, further applied within the space of advertising. His study advanced the 'third space' as a deep structure of society standing for an ambivalent cultural space that questions the Western epistemologies from a postcolonial perspective. As identity represents a highly visual side of the Self culturally inscribed within discourse that transgresses beyond ontological clash of civilizations. At this point we can claim the 'third space' as the ultimate "discursive strategy of the moment of interrogation, a moment in which the demand for identification becomes, primarily, a response to other questions of signification and desire, culture and politics" (Bhabha, 1994: 49-50). Even though emerging from literature-based corpus of study, this applies to a large extent in the case of tourism advertising, within the narratives that interrogate subtleties of the enunciations of the Other. The dislocation of culture no longer takes place at the boundaries of nations, but of discourses, in a mimetic turn that signifies and translates identities within the 'ambivalent' space of the advertising's text and image. Places become symbolic reiterations of cultural identity, mere capital of signification uncannily performing the ambivalent desire of being consumed by the potential tourists.

\section{Study Case}

$\mathrm{I}_{\mathrm{o}}^{\mathrm{n}}$ order to exemplify our theoretical ongoing, we have chosen three touristic country audio-visual commercials for Egypt, New Zeeland and Singapore. We are interested in analyzing the role played by the concepts 'place' and 'land' in the economy of the text. At the same time we shall focus on the process of signification that creates the premises of tourism advertising as a discourse of identity placed beyond the real spatial realm of the destination.

As a service industry, tourism is fundamentally - and, at times, solely - semiotic in nature because, like advertising and marketing, a key part of what is actually produced and consumed is the semiotic context of the service. (Thurlow, C., Jaworski A., 2011: 287)

We also touch upon the relevance of the autonomous promotional language of tourism (Dann, 1996), deployed at the level of cultural clichés, under semiotic and ontological circumstances.

Firstly, in Egypt's case (2016), the text written on the screen is organized in contradictions that are presented as the Unique Selling Proposals of the destination, in our view. The demonstrative 'this' is clearly playing the role of marking the spatial boundaries of the destination. The repetition of the term 'story' might stand for a tautological proof of De Certeau's theory: the touristic destination becomes the very place as a summa of stories created by the collective mental of the locals and transformed into a promotional scenario. This also comes into a nexus with the enumeration standing for the cultural patterns of entertaining; the deeper signification, according to one of the visual clichés proposed within the classification of discursive techniques in tourism promotional language (Dann, 1996): the mask/the tattooed body (Crăciunescu, 2018). On the other hand, "if advertising represents the disguise of the meaning 
(Péninou, 1972: 38) semiotics intends to de-mask the meaning" (Crăciunescu, 2018: 145): "This is our story. Our drama. Our theatre. Our poetry. Our choreography"3. The space of the commercial may represent a theatrical frame for the real place in the destination. Authenticity is also imbedded within the enumeration through the repetition of the possessive pronoun 'our':

"This is a wakeup call and a bedtime story

A first impression and second thoughts Everything and nothing

This is a postcard and a late night post A private pool and a public transportation

Holding on and letting go

A friendly local and a local friend

This is a classroom and a playground

This is a long story. This is our story.

Our drama. Our theatre. Our poetry.

Our choreography.

Our welcome.

This is Egypt." ${ }^{4}$

In the second example, a commercial for New Zeeland (2018), the leitmotif of the text, spoken by an in off voice is the land. In this case, we may consider that "discourse is treated as a multimodal resource. For example, [...] 'landscape' can be viewed as a discourse for the organization of 'land' under tourist gaze" (Jaworski, Pritchard, 2005: 5). The verbal clichés, as stated by the classification of the verbal techniques in tourism (Dann 1996), are maintained through the words: 'welcome', 'journey', 'discover', 'home', 'extraordinary'. The non-verbal clichés are related at the level of tourist-hosts interaction: the typical aboriginal greeting, example. At the same time, the discourse of the present case is typical for the classification of the three myths in tourism industry, designed in a postcolonial understanding: the myth of the untamed ${ }^{5}$ (Echtner, Prasada, 2003 in Tuker; Akama, 2009: 511). The idea of a virgin land ("our mountains, our lakes our people") offered by the locals responds to the ontological sample of Hollinshead, standing for a postcolonial manifestation as a still inherited side of tourism discourse (the sample of the deep and often hidden meaning, in foreign places, of sites and stories of the resident host population there, Hollinshead, 2004). This repertoire of an 'authentic' land as a part for the whole, that is as an excerpt of the genuine nature of our planet is comprised within the boundaries of "this extraordinary part of the world". Moreover, speech is transferred to the land as the very Transmitter, as an anthropomorphic permutation of the Logos. We may also assist to a dialectic relocation of the subaltern figure (Spivak 2008) - here the host - through a suite of conditionals while the keying technique (Dann 1996) is still employed through the imperative verbs directly addressed to the potential Receiver:

"If these lands would speak, what would they say?

They would say: welcome

They would invite you in

To share this extraordinary part of the world

This place it's yours too

This land is wide open for sharing.

Our culture welcomes all cultures

So let us show you around

Lead you to our natural wonders.

And throw your head first into our beautiful countryside 
Because what you'll find down here What you'll hear within our mountains, our lakes, our people What you'll discover on your journey throughout this precious land Is that you're welcome here Make yourself at home."

The last case, the video-clip presented within the recent touristic campaign for Singapore (2017) maintains the stereotypes of discursive strategies of tourism. The destination is presented as the very 'home' for the locals that can become a 'place' at superlative reiterating home as the ultimate 'stage' for the tourists. As Gadamer seizes the several faces of the German word Schau, included in "formulations such as 'scene' (Schauplatz, Schaububne), [...], or 'to contemplate something' (etwas beschauen) or even in "being a spectator' (zuschauen)" (Apud Crăciunescu, 2018: 140).

"There is no place like this

This is the place

This is the place I call home

Our home.

[...]

This is where who your were will not be who you will become<smiles></smiles>

This is your stage."

We have analyzed the tourism advertising under the lens of what Bhabha considers the 'third space', as due to the displacement of place as authenticity within the space of a virtual manifestation of meaning. Yet, MacCannell's concern might be confirmed within the very self-recognition of tourism as a simulacrum:
Reality and authenticity itself were covertly staged as tourism became increasingly institutionalized and commercialized. What the tourist believed was the real thing - the backstage of the lives of the others - was in fact a front-stage which had been set up in advance. (Dann, 1996: 8)

At the same time, the tourist's gaze (Urry, 2011) confers tourism a highly imbedded role in the visual turn that took place within semiotics or even tourist studies:

The place of tourism in visual culture, as spectacle, voyeurism, metaphor or phantasmagoria, is well established but seemingly so embedded that it is somewhat neglected or overlooked in what might be described as a problem of ubiquity - both of images and tourism itself (Burns et al, 2010: XVII).

The tourist's gaze as an authority in a foucauldian understanding, initially manifested within the real space of the destination, is now transferred in front of the screens, in a dialectics of choice and virtual consumption of the touristic signs. The 'third space' - the touristic advertising - represents the ambivalent discourse of selected places of identity that the potential tourist's gaze might decipher along a semiotic process.

The very consumption of touristic signs within the space of advertising as a premise for the real immersion in the destination reinforces the panoptic nature of media in general and of the tourist's gaze as a normative selection of the cultural realms in a global approach of otherness. 


\section{Works Cited}

Appadurai, A. (1996) Modernity at Large. Cultural Dimensions of Globalization, vol. 1, University of Minnesota Press.

Bauman, Z. (2003) “The tourist syndrome” in Tourist Studies, vol. 3, no. 2, pp. 205-217.

Bhabha, H.K. (1994) The Location of Culture, Routledge.

Bourdieu, P. (1982) Ce que parler veut dire: l'économie des échanges linguistiques, Fayard.

Bruno, O. (2000) Observer la communication. Naissance d'une interdiscipline, CNRS Éditions, Paris.

Burns, P, Palmer, C., Lester, J.-A. (2010) Tourism and Visual Culture. Theories and Concepts, vol. 1, CABI. Certeau de, Michel (1984) The Practice of Everyday Life, University of California Press.

Cohen, E. (1984) "The Sociology of Tourism: Approaches, Issues and Findings" in Annual Review of Sociologyvol. 10, pp. 373-392.

Crăciunescu, A. (2018) Strategii semio-discursive în publicitatea din domeniul turismului, Presa Universitară Clujeană.

Dann, G. (1996) The Language of Tourism. A Sociolinguistic Perspective, CAB International.

Echtner, Charlotte, M.; Prasad, Pushkala (2003) “The Context of Third World Tourism Marketing”, Annals of Tourism Research, 30(3), pp. 660-692.

Guba, E.; Lincoln, Y. S. (1998) Competing paradigms in qualitative researchin Denzin N. K.; Lincoln Y. S. (eds.) The Landscape of Qualitative Research: Theories and Issues. Thousand Oaks, CA: Sage.

Jaworski, A., Pritchard, A. (2005) Discourse, communication and tourism, Clevedon.

Jaworski, A.; Thurlow, C. (2010) Language and the globalizing habitus of tourism: A sociolinguistics of fleeting relationships, pp. 255-286, in N. Coupland, The Handbook of Language and Globalization,Blackwell Publishing.

Péninou, G. (1972) Intelligence de la publicité. Étude sémiotique, Robert Laffont, Paris.

Phillmore, J.; Goodson J. (2004) Qualitative Research in Tourism Ontologies, Epistemologies and Methodologies, Routledge.

Spivak, G. (1988) “Can the subaltern speak?”, in Cary Nelson and Lawrence Grossberg (eds.) Marxism and the Interpretation of Culture, London: Macmillan.

Tuker, A; Akama J. (2009) “Tourism as Postcolonialism”, in Jamal T.; Robinson, M., The SAGE Handbook of Tourism Studies, SAGE Publications, UK

Urry, J. (2011) The Tourist Gaze, Sage Publications Ltd. UK.

\section{Notes}

1.1. The authenticity perspective - tourism as a language of authentification;

2. The strangerhood perspective - tourism as a language of differentiation;

3. The play perspective - tourism as a language of recreation;

4. The conflict perspective - tourism as a language of appropriation (Dann, 1996).

2. "1. the ontological question - what is the form and nature of reality, and what can be known about reality?

2. the epistemological question - what is the nature of the relationship between the researcher and what can be known?

3. the methodological question - how can the researcher find out what she/he believes can be known?" (Guba and Lincoln, 1998).

3. Source: https://www.youtube.com/watch?v=mfxQy5A_tHs.

4. Ibid.

5. The other myths of the classification are: the myth of the unchanged and the myth of the unstrained.

6. Source: https://www.youtube.com/watch?v=Atf_Af1q_5w.

7. Ibid.

8. Source: https://www.youtube.com/watch?v=BJE3HIkQ4zU. 